Jpn. J. Phys. Fitness Sports Med. 2006, 55 Suppl. : S23 \$24

\title{
FORCE OUTPUT IN MUSCLE FIBERS DURING REPETITIVE STIMULATION IN HUMANS
}

\author{
MifuYu KAMO ${ }^{1)}$ and SHIGERU MORIMOTO ${ }^{2)}$
}

\begin{abstract}
The evoked force was observed during repetitive electrical stimulation for 3 min on $\mathrm{m}$. vastus medialis. The stimulus frequency was $0.2 \mathrm{~Hz}, 10 \mathrm{~Hz}$ and $20 \mathrm{~Hz}$. The time to peak of twitch was $90.8 \mathrm{~ms}$ at $0.2 \mathrm{~Hz}$ stimulation. The changes in the evoked force did not represent a constant or a monotonic pattern but were complex at $10 \mathrm{~Hz}$ and $20 \mathrm{~Hz}$ stimulations. At $10 \mathrm{~Hz}$ the evoked force represented an initial transient increment (steep peak), then an abrupt decrement followed by a gradual increase (gentle peak) and then a gradual decrease. At $20 \mathrm{~Hz}$ the steep phase did not appeared. The magnitude of potentiation was not necessarily large at $20 \mathrm{~Hz}$. These results suggest that a constant discharge rate of motor units cannot maintain constant force development, and "rate coding" is considered to be necessary for keeping a constant force.
\end{abstract}

(Jpn. J. Phys. Fitness Sports Med. 2006, 55 Suppl : S23 S24)

key word : Constant frequency stimulation, Evoked force change, Potentiation

\section{INTRODUCTION}

We have reported that the spike interval of motor units (MUs) gradually elongated during the initial period of voluntary isometric contraction at a constant low force level (below 10\% maximal voluntary contraction $(\mathrm{MVC}))^{1,2)}$. Though the developed muscle force was a constant, the MU decreased its firing rate. In order to investigate the contractile property of motor unit at the elongation phase, we observed the changes in the evoked force of muscle fibers under electrical stimulation at two constant frequencies, one high and one low, within motor unit firing rates.

\section{METHODS}

Experiments were performed on m. vastus medialis in six volunteers. In a sitting posture; the knee angle of the subject was set at 90 degrees by strapping the ankle joint with a belt connected to the force transducer. Muscle fibers were stimulated transcutaneously at the motor end-plate zone for 3 min. The electrical stimulation was a square pulse of $1 \mathrm{~ms}$ duration. To select stimulus intensity, we obtained the relationship between the time to peak of twitch (CT) and stimulus intensity, and employed the minimum level of stimulus intensity at which the CT became constant (even though the intensity increased). We employed three stimulation frequencies, $0.2 \mathrm{~Hz}, 10 \mathrm{~Hz}$ and $20 \mathrm{~Hz}$. The $0.2 \mathrm{~Hz}$ was selected to observe twitch responses. The $10 \mathrm{~Hz}$ was chosen as it correspond to almost the lowest firing rate of motor units, and $20 \mathrm{~Hz}$ because as it correspond to almost the highest. The evoked electrical response ( $M$-wave) was recorded from the fascicle by bipolar surface electrodes. The evoked force and $\mathrm{M}-\mathrm{wave}$ were recorded on a digital audiocassette tape using a PCM data recorder.

\section{RESULTS}

1) Twitch response observation at $0.2 \mathrm{~Hz}$ stimulation

CT of twitch response was $75 \sim 90 \mathrm{~ms}$ in the tested fascicles. In an additional experiment, we observed the twitch response of single MUs with recruitment threshold force ( $\mathrm{Fth}$ ) below 4\%MVC by using spike trigger averaging method. The CT of MUs was in the range from 75 to $85 \mathrm{~ms}$.

2) Changes in the evoked force at $10 \mathrm{~Hz}$ and $20 \mathrm{~Hz}$ stimulation

The evoked force was not constant at both fre-

\footnotetext{
${ }^{1)}$ Laboratory of Exercise Physiology, Japan Women's College of Physical Education, Tokyo, Japan

${ }^{2)}$ Laboratory of Applied Physiology, Yokohama National University, Yokohama, Japan
} 
quencies. The evoked forces of $10 \mathrm{~Hz}$ stimulation were incompletely fused tetanic contraction. The peak evoked force changed complexly, with an initial transient increment, an abrupt decrement, and a gradual increase followed by a gradual decrease. The gentle peak appeared at about 15 secs. On the other hand, at $20 \mathrm{~Hz}$ the initial transient peak did not appear, the evoked force steeply fused by $200 \mathrm{~ms}$, and then gently increased for about $10 \mathrm{sec}$ before decreasing. The magnitude of potentiation was not necessarily large at $20 \mathrm{~Hz}$.

\section{DISCUSSION}

In general, during percutaneous electrical stimulation MUs are recruited in a reversed sequence compared with voluntary contraction; that is, from fast type to slow type MUs. However, the size and the morphological organization of the axonal branches can also influence the order of activation ${ }^{3)}$. In the present study, we employed the stimulus intensity at which CT leveled off in the relationship between CT and stimulus intensity. Additionally, the CT of the stimulated fascicle was similar to the CT of the sing1e MUs with Fth below 4\%MVC. Therefore, in our experiments, slow type MUs were also activated during repetitive stimulation.
The force response in human muscle fascicle to constant frequency stimulations were not constant but had complicated changes. Our findings suggest that in voluntary contraction the constant of spike interval of MUs cannot keep a constant muscle force. Gradual elongation of MUs spike interval lowers and/or flattens the gentle peak because the elongation decreases the degree of force summation. The rate coding of MUs is an important mechanism in keeping a constant force.

\section{Acknowledgments}

This work was partly supported by "Academic Fronter Project of JWCPE, 2005.

\section{REFERENCES}

1) Kamo M. and Morimoto S. Discharge properties of human motor units during low level contraction. J. Electromyogr. Kinesiol., 11 : 255-261, 2001.

2) Kamo M. Discharge behavior of motor units in knee extensors during the initial stage of constant-force isometric contraction at low force level. Eur. J. Appl. Physiol., 86 : 375-381, 2002.

3) Feiereisen P., Duchateau J. and Hainaut K. Motor unit recruitment order during voluntary and electrically induced contractions in the tibialis anterior. Exp. Brain Res., 114 : 117-123, 1997. 